\title{
Diagnosis of molar pregnancy and persistent trophoblastic disease by flow cytometry
}

\author{
J DIANE HEMMING, ${ }^{*}$ P QUIRKE, ${ }^{*}$ C WOMACK, $\dagger$ M WELLS, ${ }^{*}$ C W ELSTON, $\dagger$ \\ C C BIRD*
}

From the Departments of Pathology, ${ }^{*}$ University of Leeds, Leeds, and †City Hospital, Nottingham

SUMMARY Histopathological assessment and flow cytometric analyses were carried out on 32 placentas (representative of each trimester) and 88 molar pregnancies. Three first trimester placentas were triploid, and the remaining 29 placentas were diploid. Of the 88 cases originally diagnosed as molar pregnancies, 26 were triploid (two complete moles, 20 partial moles, and four hydropic abortions); 59 were diploid (46 complete moles, 10 partial moles, three hydropic abortions); one was tetraploid (partial mole); and two were DNA aneuploid (one partial mole, one complete mole). A significantly increased hyperdiploid fraction (a measure of cell proliferation) was detected in diploid complete moles $(p<0.0001)$ and cases of persistent trophoblastic disease $(p<$ 0.001 ) when compared with diploid placentas and diploid partial moles. All seven cases of established persistent trophoblastic disease, for which follow up was available, were diploid and showed high hyperdiploid fractions within the range for diploid complete moles. These findings suggest that flow cytometric DNA measurements may be an important aid in the diagnosis of molar pregnancy. The high degree of cell proliferation found in this study may explain the premalignant potential of complete hydatidiform moles.

The distinction between partial moles and complete moles and their differentiation from hydropic abortions is a recurring and common problem for histopathologists. ${ }^{1}$ The use of cytogenetic techniques, ${ }^{2-6}$ morphological studies, ${ }^{7-8}$ and enzyme markers ${ }^{3-4}$ have been of some assistance in making these distinctions. Complete moles are diploid, usually $\mathbf{X X}$ (rarely XY), ${ }^{9-12}$ and are androgenetic in origin. ${ }^{2}$ It has been suggested that complete moles with a $46 \mathrm{XY}$ karyotype may be more likely to progress to persistent trophoblastic disease ${ }^{12}$ than complete moles with a 46XX karyotype. Partial moles are usually considered to be triploid (XXX or XXY), showing fetal presence and a maternal chromosomal contribution. ${ }^{5}$

The subdivision of molar and hydropic gestations has considerable prognostic importance. About $10 \%$ of patients with complete moles develop persistent trophoblastic disease, ${ }^{13}$ including the entities of invasive mole and choriocarcinoma, and a mole is the preceding gestation in at least half of all cases of choriocarcinoma. ${ }^{14}$ At present, the malignant potential of partial moles is uncertain. ${ }^{131516}$ There are at least three published cases of persistent trophoblastic disease $\mathrm{i}^{17-19}$ and one case of fatal metastic choriocarcinoma $\mathrm{a}^{20}$ developing after the diagnosis of a putative partial mole. It has been recommended that the clinical management of partial moles should be no different from that of complete moles, ${ }^{13}$ but this may result in unnecessary follow up of patients, which is both time consuming and expensive.

We have therefore investigated whether the identification of patients likely to progress to persistent trophoblastic disease could be assisted by flow cytometric analysis of DNA content.

\section{Material and methods}

\section{CASES STUDIED}

Sixty one placentas (representative of each trimester) and 114 molar pregnancies were retrieved from the files of the pathology departments of Leeds General Infirmary, Leeds, and the City Hospital, Nottingham.

\section{PATHOLOGY}

Routine $5 \mu \mathrm{m}$ sections of all specimens, stained with haematoxylin and eosin, were reviewed independently by four histopathologists; a consensus diagnosis was used for comparison with flow cytometry. The placentas were subdivided into first, second, and third 
trimester types, nearly all of which showed focal hydropic change on histological examination. The molar gestations were subdivided into complete moles and partial moles using previously accepted criteria. 1782122

\section{Complete moles}

Complete moles show pronounced hydropic change of all villi with central cistern formation. There is gross haphazard hyperplasia of both cytotrophoblast and syncytiotrophoblast with complete absence of fetal blood vessels and other features of fetal presence.

\section{Partial moles}

In partial moles hydropic change is focal with normal placental tissue in other areas. Blood vessels containing fetal red cells are often found together with other evidence of fetal presence. Trophoblastic hyperplasia is usually focal and mild. A further characteristic of partial moles are villi with irregular outlines and trophoblastic inclusions. A few partial moles may show a greater degree of trophoblastic hyperplasia, which is more characteristic of complete moles. ${ }^{13}$ Trophoblastic hyperplasia is an essential feature in differentiating partial moles from simple hydropic abortions.

\section{Persistent trophoblastic disease}

This condition results from persistence of trophoblastic tissue following a hydatidiform mole and includes the pathological entities of invasive mole and choriocarcinoma.

\section{FLOW CYTOMETRY}

Nuclear DNA measurements were performed using a modification of the method of Hedley et al. ${ }^{23}$ Briefly, $50 \mu \mathrm{m}$ sections were cut from paraffin embedded material and transferred to glass slides. The sections were dewaxed in xylene and rehydrated by passing them through a series of alcohols $(100 \%, 95 \%, 90 \%$, $70 \%$, and $50 \%$ ). They were then washed twice in distilled water. The tissue was removed from the slide with a scalpel, placed in a test tube with $0.5 \%$ pepsin (Sigma Chemical Company, Poole) in $0.9 \%$ sodium chloride adjusted to $\mathrm{pH} 1.5$ with $2 \mathrm{~N}$ hydrogen chloride, and incubated at $37^{\circ} \mathrm{C}$ for 30 minutes in a waterbath. The cells were centrifuged at $2000 \mathrm{rpm}$, washed twice in distilled water, and stained by suspension in a solution $(1 \mu \mathrm{g} / \mathrm{ml})$ of 4'-6'diamidine-2-phenylindole dihydrochloride (Boehringer Mannheim, West Germany) in RPMI 1640 tissue culture medium at $20^{\circ} \mathrm{C}$ for 30 minutes. The cells were then syringed and filtered through four layers of muslin. Samples were analysed on a EPICS V flow cytometer (Coulter Electronics, Hialeh, Florida, USA). For excitation, a

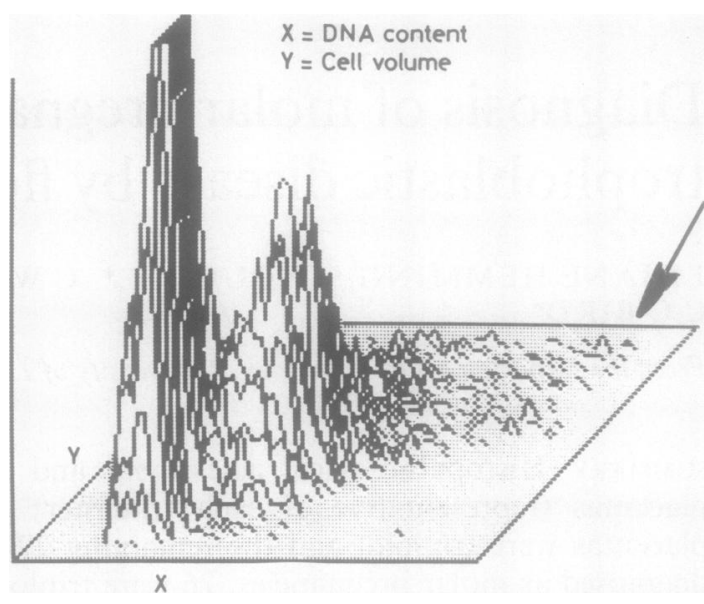

Fig 1 Two parameter analysis of DNA content $v$ volume measured by Coulter volume accessory showing proliferating cells from tetraploid $G 0 / G I$ peak, which indicates polyploidy (arrow).

Coherent Innova-90 5W UV enhanced argon ion laser was used at $50 \mathrm{MW}$ at a wavelength of $350 \mathrm{~nm}$. A $408 \mathrm{~nm}$ interference filter removed scattered incident fluorescence.

Ten thousand nuclei were counted. DNA aneuploidy was defined as the presence of more than one G0/G1 peak. ${ }^{24}$ The DNA index was calculated for DNA aneuploid samples, this being the ratio of the modal channel number of the abnormal G0/G1 peak to the modal channel number of the diploid G0/G1 peak. ${ }^{24}$ Triploidy was defined as those cases with a DNA index of 1.4-1.6. Maternal tissue (decidua) for each case was used as an internal standard.

Definite evidence of polyploidy in the form of a small tetraploid population was present within the complete moles (fig 1). Because of this, cell cycle analysis was rendered invalid by standard cell cycle computer programs, and quantitation only of the number of cells with a DNA content greater than the 2c G0/G1 peak was performed. This fraction of cells, as a percentage, was termed the hyperdiploid fraction. Because of overlap of cell populations no attempt was made to measure the hyperdiploid fraction in the DNA triploid, DNA tetraploid, and DNA aneuploid samples. The relatively high mean half peak coefficient of variation (CV) of $9 \%$ in this series did not affect the ability to detect triploid populations. A high $\mathrm{CV}$ reduces the ability to detect minor ploidy abnormalities, but when dealing with two distinctly separate populations with major ploidy abnormalities, as in this study triploidy is detectable at CVs as high as $25 \%$. A CV of $14 \%$ was used as the upper cut off level. 


\section{DEFINITIONS}

Diploid, triploid, and polyploid tissue contain exact multiples of the haploid genome (n).

\section{Diploid (2n)}

Diploid tissue contains 46 chromosomes and would yield a single $\mathrm{G} 0 / \mathrm{G} 1$ peak on a DNA histogram with a DNA index of 1.0 .

\section{Polyploidy (4n, $8 n$, and so on)}

Polyploidy is a state where exact multiples of the normal diploid (n) genome are found. On a DNA histogram G0/G1 peaks would be seen at DNA indices of 1.0 and 2.0 if $2 n$ and $4 n$ populations were present and a further peak at $4 \cdot 0$ if an 8 population was found.

\section{Triploid (3n)}

Triploid tissue contains three sets of the haploid genome. In the presence of diploid maternal decidua and triploid molar tissue two peaks would be present at DNA indices of 1.0 and 1.5 .

\section{STATISTICAL ANALYSIS}

Groups were compared using the Mann-Whitney U test and, where stated, the Kruskal Wallis test. Distribution of the hyperdiploid fraction for each group was expressed as the median value with the 5 th and 95th centiles.

\section{Results}

\section{PLACENTAS}

Twenty nine of the 61 placentas studied were unsuitable for flow cytometric analysis, probably because of poor fixation. Three of the first trimester placentas $(n=14)$ were triploid; the other 11 diploid placentas

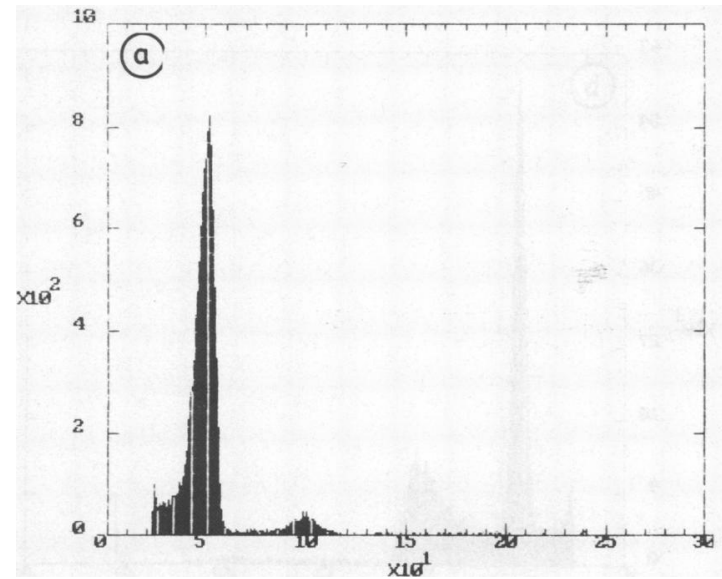

showed a median hyperdiploid fraction of $16.6 \%$ (5th-95th percentiles $=6.7 \%-20 \cdot 8 \%$ ) (fig 2). The median hyperdiploid fractions for the second $(n=10)$ and third $(\mathrm{n}=8)$ trimester placentas were $11.8 \%$ (5th-95th percentiles $=6 \cdot 7 \%-20 \cdot 7 \%)$ and $14.2 \%$ (5th-95th percentiles $=13.0 \%-19.0 \%$ ), respectively. The overall median hyperdiploid fraction for all diploid placentas was $14.9 \%$ (5th-95th percentiles $=6.8 \%-22.4 \%$ ) (table 1 ). No significant difference in the hyperdiploid fraction was found between the first, second, and third trimester placentas (Kruskal Wallis test).

\section{MOLAR GESTATIONS}

Ploidy status

Twenty six of the 114 molar gestations were unsuitable for flow cytometric analysis. Of the remaining 88 , 59 were diploid, 26 triploid, one tetraploid, and two DNA aneuploid with DNA indices of 1.22 and $2 \cdot 3$, respectively (table 2 ).

Table 1 Median percentage hyperdiploid fractions for placentas

\begin{tabular}{lcl}
\hline & No & $\begin{array}{l}\text { Median \% hyperdiploid fraction } \\
\text { (5-95th percentiles) }\end{array}$ \\
\hline $\begin{array}{l}\text { First trimester } \\
\text { Second trimester }\end{array}$ & $14^{*}$ & $16 \cdot 6(6 \cdot 7-20 \cdot 8)$ \\
Third trimester & 10 & $11 \cdot 8(6 \cdot 7-20 \cdot 7)$ \\
Overall & 8 & $14 \cdot 2(13 \cdot 0-19 \cdot 7)$ \\
\hline
\end{tabular}

*Includes three triploid placentas which were excluded for the calculation of the hyperdiploid fraction in the first trimester placentas.

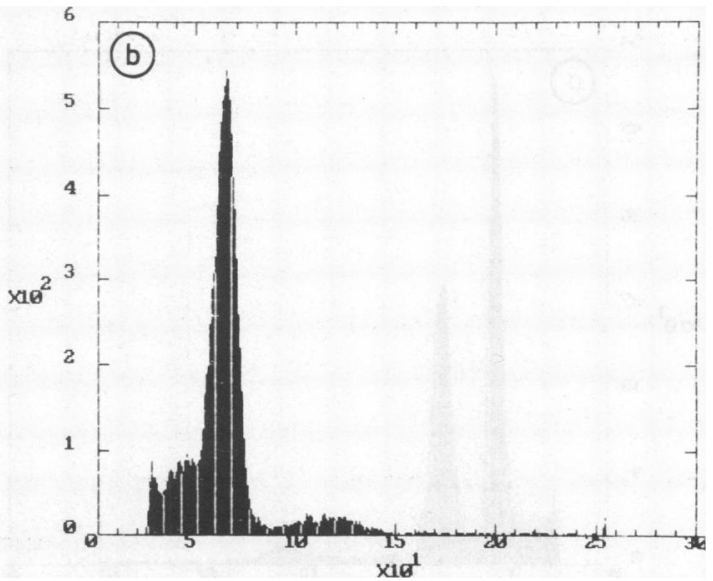

Fig 2 DNA histograms: (a) diploid placenta; (b) diploid partial mole. 
Table 2 Ploidy status and histological diagnosis of molar pregnancies

\begin{tabular}{lrrll}
\hline & \multicolumn{3}{c}{ Histological diagnosis } \\
\cline { 2 - 5 } Ploidy status & & $\begin{array}{l}\text { Complete } \\
\text { mole }\end{array}$ & $\begin{array}{l}\text { Partial } \\
\text { mole }\end{array}$ & $\begin{array}{l}\text { Hydropic } \\
\text { abortion }\end{array}$ \\
\hline Diploid & 59 & 46 & 10 & 3 \\
Triploid & 26 & 2 & 20 & 4 \\
Tetraploid & 1 & -1 & 1 & - \\
Aneuploid & 2 & 1 & 1 & - \\
Total & 88 & 49 & 32 & 7 \\
\hline
\end{tabular}

\section{Histopathological diagnosis}

Forty six complete moles, 10 partial moles, and three hydropic abortions were diploid. Twenty partial moles, two complete moles, and four hydropic abortions were triploid. The one tetraploid molar gestation was considered to represent a partial mole. The two molar gestations showing DNA aneuploidy were classified as a complete mole and a partial mole.

\section{Diploid molar gestations}

Analyses of the 59 diploid molar gestations proved interesting. The $\mathbf{4 6}$ diploid molar gestations classified as complete moles (fig 3) showed a median hyperdiploid fraction of $42 \cdot 2 \%$ (5th-95th percentiles $=23.3 \%-56 \cdot 2 \%$ ), which is well outside the range for placentas $(p<0.0001)$. Included with these 46 cases were seven clinically confirmed cases of persistent trophoblastic disease, including invasive mole. The median hyperdiploid fraction for these was $38.8 \%$ (5th-95th percentiles $=30 \cdot 2 \%-51 \cdot 5 \%$, which is within the range for diploid complete moles (NS) and outside that for placentas $(p<0.0001)$. The 10 diploid molar gestations classified as partial moles (fig 2) showed a median hyperdiploid fraction of $16 \cdot 8 \%(5$ th-95th percentiles $=10 \cdot 1 \%-26 \cdot 6 \%)$, which is almost completely within the range of placentas but significantly different from that for diploid complete moles $(p<0.0001)$ and the seven cases of persistent trophoblastic disease $(p<0.001)$ (fig 4). Three of the diploid molar gestations were reclassified as hydropic abortions and showed hyperdiploid fractions of $20 \cdot 1 \%, 18 \cdot 0 \%$, and $8 \cdot 8 \%$, falling within the range for placentas.

\section{Triploid molar gestations}

None of the 26 triploid molar gestations (fig 3) included examples of persistent trophoblastic disease.

\section{Discussion}

For histopathologists the distinction between complete moles and partial moles and their differentiation from hydropic abortions is not easy, ${ }^{1}$ especially when there is no access to cytogenetic techniques or the tissue is unsuitable for chromosomal analysis. We have found that the present histological and morphological criteria are not as reliable in practice as has been suggested by other workers. ${ }^{825}$ Assessment of the degree of villous hydropic swelling and trophoblastic hyperplasia can be highly subjective. Central cistern formation within villi can be seen in both partial moles and complete moles along with trophoblastic "inclusions" and scalloping of villi. ${ }^{78}$ Probably the most useful histological criterion for differentiating partial moles from complete moles (in the absence of cytogenetic techniques) is the presence of fetal parts, including fetal red blood cells within the villous vasculature of partial moles. ${ }^{8}$ It could be argued even in

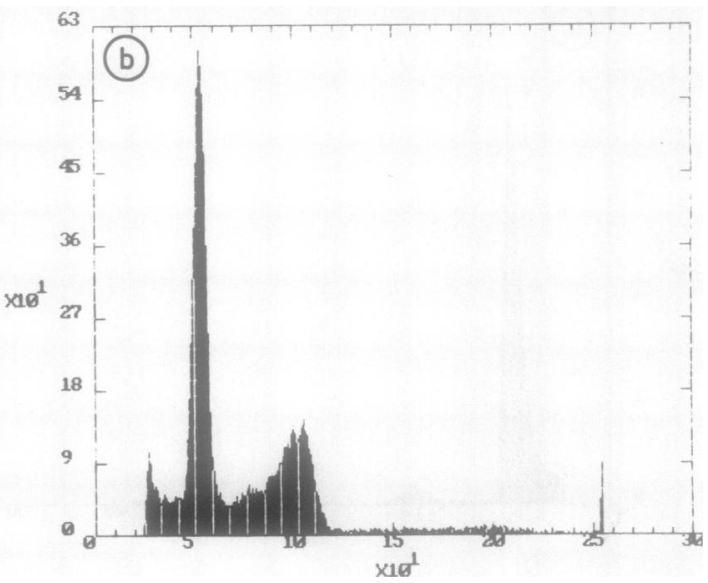

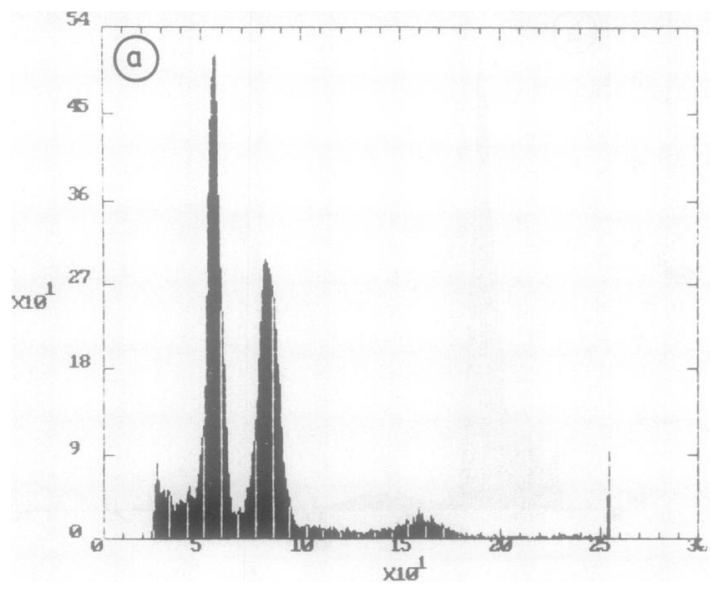

Fig 3 DNA histograms: (a) triploid partial mole; (b) diploid complete mole. 


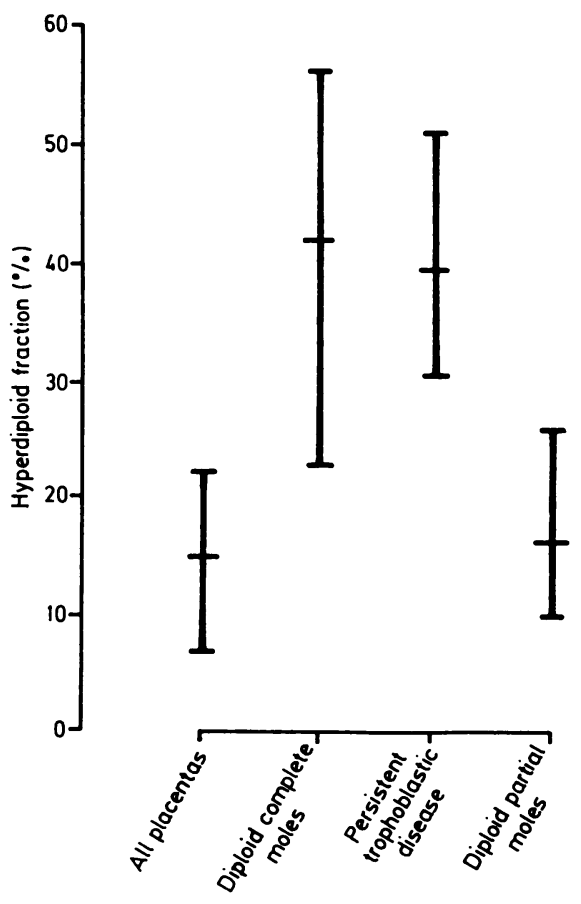

Fig 4 Median percentage hyperdiploid fractions (5th-95th percentiles) for all diploid placentas and molar pregnancies. Significant differences were shown between placentas and diploid complete moles $(p<0.0001)$ and cases of persistent trophoblastic disease $(p<0.001)$. No significant difference was shown between placentas and diploid partial moles or between diploid complete moles and cases of persistent trophoblastic disease.

these cases that a twin pregnancy with a complete mole cannot be excluded. It is therefore important that in normal clinical practice the diagnosis of the molar pregnancy should not be made on gross and histological features alone and should take account of the clinical findings (including ultrasound examination and B-human chorionic gonadotrophin estimations) when available. ${ }^{1}$

We found that diploid complete moles exhibited hyperdiploid fractions well outside the normal range for diploid placentas ( $p>0.0001$ ) (fig 4). Among these 46 cases were seven cases of clinically confirmed persistent trophoblastic disease. These were all diploid and showed hyperdiploid fractions within the range for complete moles. Increased cell turnover is found in a variety of potentially neoplastic states - for example, ulcerative colitis. ${ }^{26}$ The increased cell proliferation (termed hyperdiploid fraction) seen in complete moles compared with that seen in normal placentas may explain the neoplastic potential of complete moles.
Statements that partial moles have no malignant sequelae have been strongly contradicted by others, ${ }^{131516}$ with three published cases of persistent trophoblastic disease ${ }^{17-19}$ and one case of fatal metastatic choriocarcinoma. ${ }^{20}$ In only one of these cases had chromosomal studies been carried out. We found that all our clinically confirmed cases of persistent trophoblastic disease were diploid with hyperdiploid fractions characteristic of diploid complete moles (fig 4). None of the partial moles in our series have yet progressed to persistent trophoblastic disease during follow up.

Partial moles are usually considered to be triploid with evidence of fetal presence and a chromosomal contribution from the female gamete. ${ }^{5}$ Not all triploid abortions are partial moles, ${ }^{2728}$ as confirmed in our series. We believe we may have isolated a third type of molar gestation, the diploid partial mole with histopathological features of a partial mole, a diploid DNA content, and a low hyperdiploid fraction more characteristic of normal placentas and hydropic abortions. These 10 cases may represent the $46 \mathrm{XX}$ partial moles described by Szulman and $\operatorname{Surti}^{78}$ and the three cases of partial mole with diploid karyotype described by Teng and Ballon. ${ }^{29}$ In the three cases described by Teng and Ballon the partial mole occurred in conjunction with a live fetus and normal placental tissue; the possibility of twin pregnancy could not be excluded. The same workers went on to suggest that the diploid partial mole is a distinct entity with malignant potential since in each of their three cases $\beta$-human chorionic gonadotrophin concentrations were increased, with two patients requiring chemotherapy. Further studies are clearly required to assess the biological behaviour of diploid partial moles.

In addition to the group of diploid partial moles flow cytometry showed one case of partial mole with a DNA tetraploid DNA content and one case each of complete mole and partial mole showing DNA aneuploidy. Occasional cases of tetraploidy have been described in both complete ${ }^{\mathbf{3 0}}$ and partial moles. ${ }^{31}$ The importance of DNA aneuploidy in molar pregnancies has not yet been established, although it is a recognised occurrence. ${ }^{5}$

Flow cytometric analysis of two of the molar gestations histologically classified as complete mole showed them to be triploid. It is possible that inadequate sampling of the molar tissue resulted in histopathological misdiagnosis. The possible entity of a triploid complete mole of androgenetic origin cannot be completely excluded, however, until further studies have been performed.

In conclusion, we believe that flow cytometric analysis of DNA content has certain advantages over current cytogenetic techniques in that analyses can be 
performed rapidly on formalin fixed, paraffin embedded tissues ${ }^{23}$ either retrospectively or at the time of receipt. The versatility of the technique is emphasised by the clear definition of the different groups obtained even with the relatively high mean CV of $9 \%$ in this series. The results of this study show that the flow cytometric measurements of DNA content may be an important aid in the accurate diagnosis of molar gestations since the ploidy status for a given specimen can be rapidly determined along with the hyperdiploid fraction in diploid cases. The use of the flow cytometer in the identification of those patients at risk of developing persistent trophoblastic disease needs to be studied further. In our series the seven cases of clinically confirmed persistent trophoblastic disease were diploid and showed hyperdiploid fractions characteristic of a complete diploid mole. As a research tool flow cytometric measurement of DNA content should provide further insight into the origins and, more importantly, the risk of persistent trophoblastic disease for each subtype of hydatidiform mole.

This work was supported by grants from the Yorkshire Cancer Research Campaign. We thank Carol L North, N Dudding, and R Stretton for technical assistance and Mrs Jacquie Fearnley for typing the manuscript.

\section{References}

1 Elston CW. The pathology of trophoblastic disease: current status. Clin Obstet Gynaecol 1984;2:135-52.

2 Kajii T, Omaha K. Androgenetic origin of hydatidiform mole. Nature 1977;268:633-4.

3 Lawler SD, Pickthall VJ, Fisher RA, Povey S, Wyn Evans M, Szulman AE. Genetic studies of complete and partial hydatidiform moles. Lancet 1979; i:580.

4 Jacobs PA, Wilson CM, Sprenkle JA, Rosenshein NB, Migeon BR. Mechanism of origin of complete hydatidiform moles. Nature 1980;286:714-6.

5 Lawler SD, Fisher RA, Pickthall VJ, Povey S, Wyn Evans M. Genetic studies on hydatidiform moles. I. The origin of partial moles. Cancer Genet Cytogenet 1982;5:309-20.

6 Lawler SD, Povey S, Fisher RA, Pickthall VJ. Genetic studies on hydatidiform moles. II. The origin of complete moles. Ann Hum Genet 1982;46:209-22.

7 Szulman AE, Surti U. The syndromes of hydatidiform mole. I. Cytogenetic and morphological correlations. Am J Obstet Gynecol 1978;131:665-71.

8 Szulman AE, Surti U. The syndromes of hydatidiform mole. II. Morphological evolution of the complete and partial mole. Am J Obstet Gynecol 1978;132:20-7.

9 Ohama K, Kajii T, Okamoto E, et al. Dispermic origin of XY hydatidiform moles. Nature 1981;292:551-2.

10 Surti U, Szulman AE, O'Brien S. Complete (classic) hydatidiform mole with $46, X Y$ karyotype of paternal origin. Hum Genet 1979;51:153-5.
11 Kajii T, Kurashige H, Ohama K, Uchino F. XY and XX complete moles; clinical and morphological correlations. Am J Obstet Gynecol 1984;150:57-64.

12 Wake N, Seki T, Fujita H, et al. Malignant potential of homozygous and heterozygous complete moles. Cancer Res 1984;44:1226-30.

13 Womack C, Elston CW. Hydatidiform mole in Nottingham; a 12 year retrospective, epidemiological and morphological study. Placenta 1985;6:93-106.

14 Elston CW. Gestational tumours of trophoblast. In: Anthony PP, MacSween RMN, eds. Recent advances in histopathology. Edinburgh: Churchil Livingstone, 1981:149-61.

15 Vassikalos P, Kajii T. Hydatidiform mole; two entities. Lancet 1976;i:259.

16 Vassikalos P, Riotton G, Kajii T. Hydatidiform mole; two entities. A morphological and cytogenetic study with some clinical considerations. Am J Obstet Gynecol 1977;127:167-70.

17 Jones NB, Lauersen NH. Hydatidiform mole with co-existent fetus. Am J Obstet Gynecol 1975;122:267-72.

18 Szulman AE, Ma HK Wong LC, Hsu C. Residual trophoblastic disease in association with partial hydatidiform mole. Obstet Gynecol 1981;57:392-4.

19 Szulman AE, Surti U, Berman M. Patient with partial mole requiring chemotherapy. Lancet 1978;ii:1099.

20 Looi LM, Sivanersaratnam V. Malignant evolution with a fatal outcome in a patients with partial hydatidiform mole. Auz NZ Obstet Gynaecol 1981;21:51-3.

21 Elston CW. Trophoblastic tumours of the placenta. In: Fox H, ed. Pathology of the placenta. London: WB Saunders, 1978:368-425.

22 World Health Organisation Scientific Group. Gestational trophoblastic diseases. Technical report series 692. Geneva: WHO, 1983.

23 Hedley DW, Friedlander ML, Taylor IW, Rugg CA, Musgrove EA. Method for analysis of cellular DNA content of paraffin-embedded pathological material using flow cytometry. J Histochem Cytochem 1983;31:1333-5.

24 Hiddemann W, Schumann J, Andreeff M, et al. Convention on nomenclature for DNA cytometry. Cytometry 1984;5:445-6.

25 Czernobilsky B, Barash A, Lancet M. Partial moles: A clinicopathological study of 25 cases. Obstet Gynecol 1982;59:75-7.

26 Franklin WA, McDonald G, Stein HO, et al. Immunohistologic demonstration of abnormal colonic crypt cell kinetics in ulcerative colitis. Hum Pathol 1985;16:1129-32.

27 Szulman AE, Phillipe E, Boue JG, Boue A. Human triploidy: association with partial moles and non-molar conceptuses. Hum Pathol 1981;11:1016-21.

28 Jacobs PA, Szulman AE, Funkhouser J, Matsuura JS, Wilson CC. Human triploidy; relationship between parental origin of the additional haploid complement and the development of partial hydatidiform mole. Ann Hum Genet 1982;46:223-31.

29 Teng NNH, Ballon SC. Partial hydatidiform mole with diploid karyotype: report of three cases. Am J Obstet Gynecol 1984;150:961-4.

30 Hunt PA, Jacobs PA. In vitro growth and chromosome constitution of placental cells II Hydatidiform moles. Cytogenet Cell Genet 1985;39:7-13.

31 Surti U, Szulman AE, Wagner K, Leppert M, O'Brien SJ. Tetraploid partial hydatidiform moles: two cases with a triple paternal contribution and a 92, XXXY karyotype. Hum Genet 1986;72:15-21.

Requests for reprints to: Dr P Quirke, Department of Pathology, University of Leeds, Leeds, LS2 9JT, England. 